\title{
Modern Hematology - a Complex Interdisciplinary Tool
}

\author{
István Benedek, Theodora Benedek
}

University of Medicine and Pharmacy, Tîrgu Mureș, Romania

\section{CORRESPONDENCE}

Theodora Benedek

Str. Gheorghe Marinescu nr. 38

540139 Tîrgu Mureș, Romania

Tel: +40 265215551

E-mail: theodora.benedek@gmail.com
István Benedek • Str. Gheorghe Marinescu nr. 38, 540139 Tîrgu Mureș, Romania. Tel: +40 265215551 E-mail: istvan.benedek@umftgm.ro
Hematological disorders are involved in a large number of systemic diseases in which complex interdisciplinary approaches are required to ensure the most effective treatment strategy. Stem cell therapy has emerged as a promising therapeutic tool, not only in patients with hematological disorders, but also in patients with acute myocardial infarction, severe heart failure, critical limb ischemia, neurological disorders, or for cartilage regeneration in various orthopedic applications. ${ }^{1,2}$ Modern bioengineering technologies made it possible to generate scaffolds impregnated with stem cells for various applications (such as patches for wound repair or for open heart surgery). ${ }^{3,4}$ It has also been demonstrated that in patients with heart failure or with coronary artery disease, correction of anemia can lead to a significant improvement of symptoms and outcomes. 5,6

Several hematological parameters carry also prognostic impact for other diseases. For instance, interventional cardiology studies demonstrated that neutrophil count, leucocyte count, or blood count-derived parameters such as red cell distribution width-platelet ratio (a new biomarker for inflammation) or neutrophil-lymphocyte ratio are significant predictors for the occurrence of no-reflow phenomenon after successful recanalization of an occluded coronary artery in the setting of an acute myocardial infarction. ${ }^{7-11}$

Therefore, hematology can be considered as an important link between various diseases, serving also as a reflection of the severity of these pathologies. This special issue of JIM is focused on the most relevant topics in modern hematology.

Bzduch et al. performed a study on the importance of FLT3-ITD gene mutation in the survival of patients with acute myeloid leukemia (AML). The authors analyzed 210 patients with AML, from which 10 presented FLT3-ITD mutation, and the results showed an overall survival rate of $7 \%(n=15)$, while patients with the specified mutation presented a $100 \%$ mortality rate $(n=10)$ within the first two months. Moreover, none of the subjects with FLT3-ITD mutation presented complete remission of the disease. ${ }^{12}$

Stem cell therapies have been used for the treatment of hematologic neoplastic diseases for over three decades, including Hodgkin and non-Hodgkin limphomas. ${ }^{13}$ Pakucs et al. aimed to evaluate complications occurring after au- 
tologous hematopoietic stem cell transplantation on 94 patients with malignant lymphomas. The analysis revealed that $18 \%$ of subjects presented confirmed infections, $42 \%$ presented electrolyte imbalances, and $36 \%$ had hypoalbuminemia. ${ }^{14}$ The results of this study underline the importance of a proper evaluation of complications that are related to stem cell therapies, in order to implement proper patient management.

Furthermore, Mild et al. performed a retrospective analysis on patients with failure of stem cell mobilization, in which the highest harvesting failure occurred in patients aged between 51 to 61 years, and all the analyzed subjects had been heavily pretreated with alkylating agents and purine analogs. Moreover, the study included patients with various types of hematological malignancies, and the results found that the highest mobilization failure occurred in non-Hodgkin lymphoma $(42 \%, \mathrm{n}=8)$, Hodgkin lymphoma $(37.5 \%, \mathrm{n}=6)$, and multiple myeloma $(21 \%, \mathrm{n}=$ 4). ${ }^{15}$ Being that autologous stem cell therapies can be a curative option for patients with various hematological cancers, further studies on the cause and factors associated with failure to harvest stem cells, as well as methods for improvement are essential.

Located at the border between hematology and cardiology, thrombosis and cardioembolic events in atrial fibrillation patients have been linked to increased systemic inflammation, hypercoagulable states, and enhanced atrial fibrosis. ${ }^{16,17}$ Oltean et al. are currently conducting a clinical observational study on atrial fibrillation patients, the FIBROS study, in which they will test the hypothesis that the degree of atrial fibrosis, in correlation with several hematological markers for inflammation, platelet aggregation, and clotting, could serve as a model for identifying the profile of patients at increased risk for cardioembolic events. ${ }^{18}$

Due to the versatile use of stem cells in various therapies, there has been an increasing interest in cellular applications, not only in hematological disorders, but also in non-healing ulcers, as well as in different types of peripheral artery disease.

This focus issue includes a case report on the effect of stem cell transplantation that led to improvement of both the hematological malignancy for which it was intended, but it also caused a significant improvement in the overall cardiac function. More specifically, Tudor $e t$ al. presented a patient with multiple myeloma, who went into the remission phase after stem cell transplantation, and presented an increase in the left ventricular ejection fraction from 50 to $60 \%$, a smaller mitral regurgitation jet, and also a lower systolic pressure in the pulmonary artery. ${ }^{19}$ The success of stem cell treatment on both the hematological condition as well as the associated cardiovascular condition is indicative of the pluripotent capacity of these novel treatments in complex patients with multiple comorbidities.

In an article published in this focus issue by Opincariu et al., the authors sought to review the current articles on the use of stem cell treatments, not only on subjects with critical lower limb ischemia, but also on several types of peripheral artery disease, caused by either atherosclerosis or thromboangiitis obliterans, including upper limb ischemia, stroke patients, renal artery stenosis, and mesenteric ischemia. ${ }^{20}$ The manuscript revealed the presence of extensive research on lower limb ischemia, which has shown promising results in restoring blood flow to no-option ischemic limbs, in which revascularization methods (surgical or interventional) either had failed, or were not suitable. ${ }^{21}$ At the same time, stem cells have been proven effective in improving motor deficits in ischemic stroke patients, but the main concern in these procedures is safety, the type of stem cell to be used, as well as the route of injection. Preclinical studies on swine and rat models are also cited by Opincariu et al. in stem cell therapeutic applications for renal artery stenosis and mesenteric ischemia, both showing promising results in the improvement of renal fibrosis and glomerular filtration rates, as well as increased survival and better recovery of the intestinal barrier after induced intestinal ischemia. ${ }^{22,23}$

Another manuscript in this issue is concerning the use of cell therapies in non-healing ulcers, published by Mester $e t$ al. The authors present a clinical update on the use of various types of stem cells, harvested from the bone marrow, adipose tissue, umbilical cord, and placenta, that present paracrine effects, trigger angiogenesis, cell proliferation, and tissue regeneration, thus inducing ulcer healing and epithelization, while simultaneously decreasing the local fibrosis. ${ }^{24}$ There is multiple evidence regarding the efficacy of stem cells in the improvement of various types of nonhealing wounds caused by skin cancer, irradiation, diabetes, and ischemia, leading to the belief that stem cells could become a first line of treatment in chronic ulcers that present no tendency for regeneration. ${ }^{25-28}$

All three manuscripts present possible prospects in stem cell therapies in hematological diseases, complex cardiovascular disorders, peripheral artery disease, and nonhealing wounds, describing the emerging use of allogeneic cells from matched HLA healthy donors, as well as the ethical and financial limitations of these methods. However, all authors mention the great therapeutic potential of stem cells in disorders in which other treatment methods have failed. 
Novel therapies in various diseases that include stem cell transplantation require a proper collaboration between a multitude of specialties. Stem cell harvesting and mobilization for their use in cardiac and vascular disorders are performed with the help several specialists including the hematologist. Various cardiovascular diseases are influenced by hematological parameters, while hematological disorders and their treatment can have great impact on the cardiovascular balance, thus underlying once again the importance of a proper collaboration between specialties for both a proper patient management, as well as in preclinical and clinical research.

\section{CONFLICT OF INTEREST}

Nothing to declare.

\section{REFERENCES}

1. Benedek T, Kovács I, Benedek I. Therapeutic Angiogenesis for Severely Ischemic Limbs - from Bench to Bedside in Acute Vascular Care. Journal of Cardiovascular Emergencies. 2017;3:160-171.

2. Tatu RF, Hurmuz M, Miu CA. ACL Primary Repair with Bone Marrow Stimulation and Growth Factors. A Review of Literature. Journal of Interdisciplinary Medicine. 2017; 2(S3):8-11.

3. Ojeh N, Pastar I, Tomic-Canic M, Stojadinovic O. Stem Cells in Skin Regeneration, Wound Healing, and Their Clinical Applications. Int J Mol Sci. 2015;16:25476-25501.

4. Hodonsky C, Mundada L, Wang S, et al. Effects of Scaffold Material Used in Cardiovascular Surgery on Mesenchymal Stem Cells and Cardiac Progenitor Cells. Ann Thorac Surg. 2015;99:605-611.

5. Mester A, Mitre A, Lazar E, et al. Anemia and Iron Deficiency in Heart Failure - Clinical Update. Journal of Interdisciplinary Medicine. 2017;2:308-311.

6. Shah R, Agarwal AK. Anemia associated with chronic heart failure: current concepts. Clin Interv Aging. 2013;8:111-122.

7. Baysal E, Çetin M, Yaylak B, et al. Roles of the red cell distribution width and neutrophil/lymphocyte ratio in predicting thrombolysis failure in patients with an ST-segment elevation myocardial infarction. Blood Coagul Fibrinolysis. 2015;26:274-278.

8. Karakas MS, Korucuk N, Tosun V, et al. Red cell distribution width and neutrophil-to-lymphocyte ratio predict left ventricular dysfunction in acute anterior ST-segment elevation myocardial infarction. J Saudi Heart Assoc. 2016;28:152-158.

9. Pereg D, Berlin T, Mosseri M. Mean platelet volume on admission correlates with impaired response to thrombolysis in patients with STelevation myocardial infarction. Platelets. 2010;21:117-121.
10. Chu SG, Becker RC, Berger PB, et al. Mean platelet volume as a predictor of cardiovascular risk: a systematic review and meta-analysis. J Thromb Haemost. 2010;8:148-156.

11. Wagdy S, Sobhy M, Loutfi M. Neutrophil/Lymphocyte Ratio as a Predictor of In-Hospital Major Adverse Cardiac Events, New-Onset Atrial Fibrillation and No-Reflow Phenomenon in Patients with ST Elevation Myocardial Infarction. Clin Med Insights Cardiol. 2016:10:19-22.

12. Bzduch A, Biro S, Sandor-Keri J, Benedek I Jr, Lazar E, Benedek I. Prognosis of patients with acute myeloid leukemia regarding the presence FLT3 gene mutation. Journal of Interdisciplinary Medicine. 2017;2:42-44.

13. Hübel K, de la Rubbia J, Azar N, et al. Current status of haematopoietic autologous stem cell transplantation in lymphoid malignancies: a European perspective. Eur J Haematol. 2015;94:12-22.

14. Pakucs A, Lazar E, Köpeczi JB, et al. Post autologous stem cell transplantation complication management in case of malignant lymphoma patients. Journal of Interdisciplinary Medicine. 2017:2:36-38.

15. Mild E, Lazar E, Köpeczi JB, et al. Stem cell mobilization and harvesting failure in case of heavily pretreated patients. Journal of Interdisciplinary Medicine. 2017;2:39-41

16. Steffel J, Luscher TF, Tanner FC. Tissue factor in cardiovascular diseases: molecular mechanisms and clinical implications. Circulation. 2006;113:722731

17. Nattel S, Harada M. Atrial remodeling and atrial fibrillation: recent advances and translational perspectives. J Am Coll Cardiol. 2014;63:2335-2345.

18. Oltean P, Korodi S, Benedek I Jr, et al. Imaging-derived biomarkers associated with atrial FIBROsis, Structural remodeling and the risk of cardio-embolic events in patients with atrial fibrillation - the FIBROS study. Journal of Interdisciplinary Medicine. 2017;2:31-35

19. Tudor C, Lazar E, Gazdac M et al. The evolution of intracardiac hemodynamics post autologous stem cell transplant in a case of multiple myeloma associated with severe tricuspid and mitral valve insufficiency. Journal of Interdisciplinary Medicine. 2017;2:45-47.

20. Opincariu D, Mester A, Benedek I, Benedek I. Stem cell therapies in peripheral vascular diseases - current status. Journal of Interdisciplinary Medicine. 2017;2:12-19.

21. Rigato M, Monami M, Fadini GP. Autologous Cell Therapy for Peripheral Arterial Disease: Systematic Review and Meta-Analysis of Randomized, Nonrandomized, and Noncontrolled Studies. Circ Res. 2017:120:13261340.

22. Eirin A, Zhu XY, Krier JD et al. Adipose tissue-derived mesenchymal stem cells improve revascularization outcomes to restore renal function in swine atherosclerotic renal artery stenosis. Stem Cells. 2012:30:1030-1041.

23. Jiang $H$, Qu L, Li Y, et al. Bone marrow mesenchymal stem cells reduce intestinal ischemia/reperfusion injuries in rats. J Surg Res. 2011:168:127-134

24. Mester A, Opincariu D, Benedek I, Benedek I. Stem cell therapy in wound healing. Journal of Interdisciplinary Medicine. 2017;2:20-24

25. Hassan WU, Greiser U, Wang W. Role of adipose-derived stem cells in wound healing. Wound Repair Regen. 2014;22:313-325

26. Procházka V, Gumulec J, Jalůvka F, et al. Cell therapy, a new standard in management of chronic critical limb ischemia and foot ulcer. Cell Transplant. 2010:19:1413-1424.

27. Haubner F, Ohmann E, Pohl F, et al. Wound healing after radiation therapy: review of the literature. Radiat Oncol. 2012;7:162

28. Maxson S, Lopez EA, Yoo D, Danilkovitch-Miagkova A, Leroux MA. Concise review: role of mesenchymal stem cells in wound repair. Stem Cells Trans/ Med. 2012:1:142-149. 